\title{
Indeks bentuk otolit ikan cakalang, Katsuwonus pelamis (Linnaeus, 1758) dari Samudra Hindia
}

\author{
[Otolith shape indices of skipjack tuna, Katsuwonus pelamis (Linnaeus, 1758) \\ from the Indian Ocean] \\ Arief Wujdi ${ }^{\bowtie}$, Maya Agustina, Irwan Jatmiko \\ Loka Riset Perikanan Tuna, \\ Jl. Mertasari No.140, Banjar Suwung Kangin, Sidakarya, Denpasar, Bali. 80223
}

Diterima: 21 Oktober 2017; Disetujui: 5 Juni 2018

\begin{abstract}
Abstrak
Ikan cakalang, Katsuwonus pelamis (Linnaeus, 1758) berperan penting dalam ekosistem perairan laut, yaitu mangsa bagi jenis hiu, kelompok billfish, dan tuna berukuran besar lainnya. Dalam hal mengungkap hubungan pemangsa dan mangsa dalam suatu rantai makanan, seringkali terjadi kekosongan informasi karena sulitnya mengidentifikasi ikan yang telah tercerna. Penelitian ini bertujuan untuk menentukan bentuk morfologi otolit ikan cakalang berdasarkan nilai indeks bentuk. Data morfometri dikumpulkan dari 253 pasang otolit ikan cakalang pada bulan Februari, April, Agustus, dan September tahun 2016 di empat tempat pendaratan ikan, yaitu: Binuangeun, Sadeng, Prigi, dan Labuhan Lombok. Data morfometri otolit diuji normalitas dan homogenitasnya masing-masing menggunakan uji Kolmogorof-Smirnov dan Levene. Uji T berpasangan juga diterapkan untuk memastikan signifikansi perbedaan antara morfometrik otolit kanan dan kiri. Penghitungan indeks bentuk menggunakan enam deksriptor, yang meliputi form factor $\left(\mathrm{F}_{\mathrm{F}}\right)$, roundness $\left(\mathrm{R}_{\mathrm{O}}\right)$, circularity atau compactness $(\mathrm{C})$, rectangularity $\left(\mathrm{R}_{\mathrm{t}}\right)$, ellipticity $(\mathrm{E})$, dan aspect ratio $\left(\mathrm{A}_{\mathrm{R}}\right)$. Analisis multivariat menggu-nakan MANOVA dan uji Tuckey juga diterapkan untuk menentukan perbedaan morfometri otolit dari masingmasing lokasi. Hasil menunjukkan bahwa data tersebar normal dan homogen serta tidak terdapat perbedaan yang signifikan pada morfometri otolit kanan dan kiri $(\mathrm{P}>0,05)$. Penelitian ini juga menyajikan nilai indeks bentuk yang menjelaskan bentuk morfologi otolit ikan cakalang, yaitu memiliki karakteristik cenderung oval, memanjang, dan memiliki permukaan yang tidak beraturan.
\end{abstract}

Kata penting: indeks bentuk; morfometri; otolit; ikan cakalang; shape R; hubungan pemangsa dan mangsa

\begin{abstract}
Skipjack tuna, Katsuwonus pelamis (Linnaeus, 1758) plays an important role in terms of the marine ecosystems as preyed-upon by shark, billfish, and larger tunas. In order to determine food chain system, there was a gap information as digested skipjack tuna difficult to be identified. This study aimed to determine shape indices to describe the otolith shape of skipjack. The morphometry data were collected from 253 pairs of skipjack tuna's otolith during February, April, August, and September 2016 from four fishing ports namely Binuangeun, Sadeng, Prigi, and Labuhan Lombok. The data normality and homogenity also determined using Kolmogorov-Smirnov and Levene test respectively. In addition, right and left otolith morphometry were investigated using paired T-test. The shape indices were calculated using six descriptors including form factor $(\mathrm{FF})$, roundness $(\mathrm{RO})$, circularity or compactness $(\mathrm{C})$, rectangularity $(\mathrm{Rt})$, ellipticity (E), and aspect ratio (AR). Multivariate test using MANOVA and Tuckey test also implemented to investigate variation among locations. The results showed that the data were distributed normally and homogenly. There were also not significantly difference on otolith morphometry between left and right side $(\mathrm{P}>0,05)$. Shape indices also provided in this paper. Skipjack tuna's otolith has performed as non-rounded, closed to oval, elongated, and irregular surface.
\end{abstract}

Keywords: shape indices; morphometry; otolith; skipjack tuna; ShapeR; predator-prey relationship

\section{Pendahuluan}

Ikan bertulang sejati (Teleostei) mempunyai otolit yang terletak di dalam telinga sehingga otolit seringkali disebut juga batu telinga (Jawad et al. 2011, Valinassab et al. 2012, Chulin \& Chen 2013). Otolit merupakan organ yang ber-

$\triangle$ Penulis korespondensi

Alamat surel: arief_wujdi@yahoo.com fungsi untuk mengatur keseimbangan, pendengaran, koordinasi arah renang, dan orientasi (Tuset et al. 2003, Popper et al. 2005, Valinassab et al. 2012, Bani et al. 2013, Cabello et al. 2014, Yilmaz et al. 2014, Sadighzadeh et al. 2014) yang ditemukan pada semua ikan bertulang sejati (Campana 2004). Otolit tersusun dari kalsium karbonat $\left(\mathrm{CaCO}_{3}\right)$ sebagai komponen utama, 
yang umumnya berbentuk aragonit dan deposit garam (Valinassab et al. 2012, Cabello et al. 2014, Sadighzadeh et al. 2014).

Otolit terdiri atas sagittae, lapillus, dan asteriscus (Campana 2004, Tuset et al. 2008). Sagittae mempunyai ukuran yang terbesar pada semua ikan, diikuti asteriscus dan lapillus sebagai yang terkecil (Jawad et al. 2008, Seyfabadi et al. 2014, Yilmaz et al. 2015). Sagittae juga relatif lebih mudah dikumpulkan (Bani et al. 2013) dan memiliki struktur yang lebih stabil dibanding lapillus dan astericus, serta memiliki ciri-ciri yang spesifik antarspesies (Polito et al. 2011). Sagittae telah digunakan secara luas untuk memperoleh pemahaman yang lebih baik dalam studi taksonomi dan identifikasi spesies, sejarah hidup, pertumbuhan, dan umur (Campana \& Neilson 1985, Sparre \& Venema 1999, Tuset et al. 2003, Homayuni et al. 2013, Reichenbacher \& Reichard 2014) karena sagittae memiliki ciri khas yang spesifik pada setiap jenis ikan, meliputi bentuk, ukuran, bobot, pola pertumbuhan, kontur, dan komposisi kimiawi (Reichenbacher et al. 2007, Zorica et al. 2010, Annabi et al. 2013). Sagittae ditemukan pula dalam jumlah yang melimpah dalam bentuk fosil sehingga digunakan dalam studi paleontologi untuk rekonstruksi keanekaragaman ikan teleostei pada masa lampau, zoogeografi, dan evolusinya (Reichenbacher et al. 2007, Zorica et al. 2010, Annabi et al. 2013).

Dalam hal identifikasi spesies ikan, khususnya dalam studi isi alat pencernaan, seringkali peneliti hanya menemukan ikan yang telah hancur akibat proses pencernaan. Hal ini mengakibatkan berkurangnya informasi jenis ikan yang dimangsa, khususnya ikan cakalang, yang menjadi mangsa bagi ikan hiu dan kelompok ikan berparuh (billfish), kelompok tuna besar lainnya dan mamalia laut, bahkan kanibalisme oleh ikan sejenis yang berukuran lebih besar (Essington et al. 2009, Fonteneau et al. 2009, Hunsicker et al. 2012). Padahal otolit dapat ditemukan dalam jumlah yang melimpah didalam alat pencernaan ikan predator (Pascoe 1986) dikarenakan otolit bersifat lebih tahan terhadap proses pencernaan (Aydin et al. 2004). Penelitian ini bertujuan untuk menentukan morfologi otolit ikan cakalang yang dikonfirmasi dalam bentuk indeks yang informasinya masih terbatas di Indonesia. Diharapkan hasil penelitian ini dapat melengkapi basis data identifikasi jenis ikan, khususnya ikan yang telah tercerna, untuk mendapatkan pemahaman yang lebih baik berkaitan dengan hubungan mangsa-pemangsa (predator-prey relationship) dalam sistem rantai makanan di ekosistem laut.

\section{Bahan dan metode}

\section{Pengumpulan data dan penanganan sampel}

Ikan cakalang yang diamati merupakan hasil tangkapan pancing ulur dan pukat cincin skala rakyat. Pengumpulan sampel dilakukan pada bulan Februari (musim barat), April (musim peralihan 1), Agustus, dan September (musim timur) tahun 2016 di empat tempat pendaratan ikan yang mewakili area Samudra Hindia selatan Jawa hingga Nusa Tenggara Timur (Wilayah Pengelolaan Perikanan Negara Republik Indonesia 573), yaitu Binuangeun, Sadeng, Prigi, dan Labuhan Lombok (Gambar 1). Data biologis yang dikumpulkan meliputi panjang cagak $(\mathrm{cm})$, bobot tubuh (gram), dan sampel otolit (saggittae). 


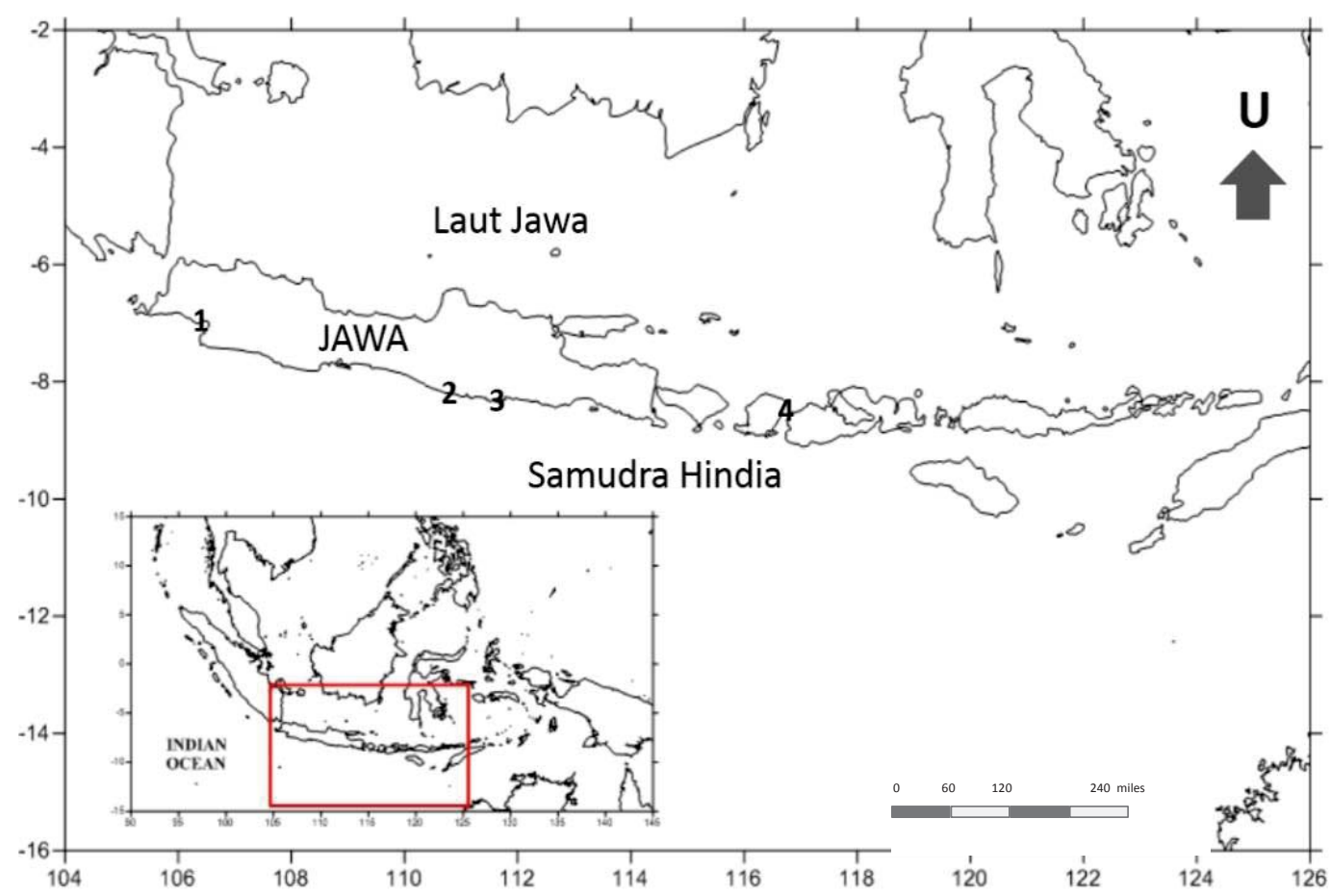

Gambar 1. Lokasi pengumpulan sampel otolit ikan cakalang (K. pelamis): 1) Binuangeun, 2) Sadeng, 3) Prigi, dan 4) Labuhan Lombok

Sampel otolit diambil dengan metode open the hatch (Secor et al. 1992), yaitu dengan membuat dua pola potongan secara vertikal dan horizontal di bagian atas kepala ikan hingga bagian otak terekspos sempurna. Selanjutnya, bagian otak dibersihkan hingga tampak rongga sacculus yang berisi otolit. Otolit diambil dengan pinset dengan bagian ujung yang lancip dan tanpa gerigi. Kemudian otolit dibersihkan dengan menggunakan kuas dan akuades untuk menghilangkan jaringan dan lendir. Pembersihan otolit dilanjutkan dengan merendam otolit kedalam ultrasonic cleaner yang berisi akuades selama 5 menit. Otolit disimpan dalam kapsul plastik (BEEM RB001 size 00) yang telah diberi label lalu dikeringkan dalam oven pada suhu $25-30^{\circ} \mathrm{C}$ selama 12 jam.

\section{Pengamatan morfometrik otolit}

Otolit yang telah dikumpulkan kemudian disortir, Hanya otolit yang utuh dan komplit (sepasang kiri dan kanan) yang dianalisis. Masing-masing otolit kiri dan kanan ditimbang menggunakan timbangan mikro (OHAUS Adventurer AX223) dengan sensitivitas 0,0001 gram untuk mendapatkan data bobot otolit (otolith mass atau $\mathrm{O}_{\mathrm{M}}$ ) dalam satuan gram. Otolit dipotret menggu-nakan stereomikroskop (Carl Zeiss Stemi 2000C) yang terkoneksi dengan kamera digital (axioCam 5MP) dengan latar belakang bewarna gelap dan perbesaran 6,5 kali sehingga menghasilkan citra dengan format berwarna (Red-Green-Blue atau RGB). Selanjutnya, citra otolit diubah menjadi format hitam dan putih (32 Bit). Manipulasi kontras dan kecerahan juga diterapkan seperlunya terhadap citra otolit menggunakan metode threshold dengan piranti lunak ImageJ yang dapat diakses secara bebas pada laman: http://rsbweb.nih.gov/ij/. 


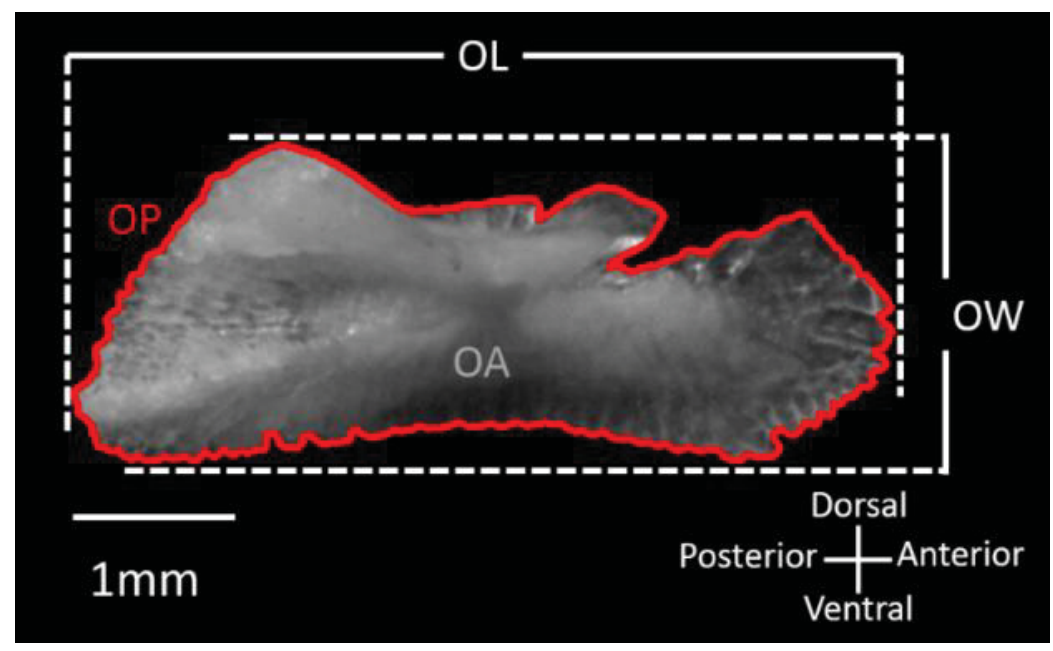

Gambar 2. Sumbu pengukuran morfometri otolit ikan cakalang (K. pelamis). Garis merah merupakan delineasi garis terluar otolit dengan paket "ShapeR" untuk menentukan morfometri otolit. Keterangan: panjang otolit $\left(\mathrm{O}_{\mathrm{L}}\right)$, lebar otolit $\left(\mathrm{O}_{\mathrm{W}}\right)$, keliling otolit $\left(\mathrm{O}_{\mathrm{P}}\right)$, dan luas otolit $\left(\mathrm{O}_{\mathrm{A}}\right)$

Data morfometrik dikumpulkan dari citra otolit secara dua dimensi dengan program $\mathrm{R}(\mathrm{R}$ Core team, www.r-project.org) dengan menggunakan paket "ShapeR" (Libungan \& Palsson 2015), meliputi ukuran panjang, lebar, keliling, dan luas otolit (Gambar 2). Panjang otolit (otolith length atau $\mathrm{O}_{\mathrm{L}}$, dalam satuan $\mathrm{mm}$ ) didefinisikan sebagai jarak mendatar terjauh antara bagian anterior dan posterior. Lebar otolit (otolith width atau $\mathrm{O}_{\mathrm{W}}, \mathrm{mm}$ ) merupakan jarak terjauh secara vertikal antara bagian dorsal dan ventral. Keliling otolit (otolith perimeter atau $\mathrm{O}_{\mathrm{P}}, \mathrm{mm}$ ) merupakan panjang total garis terluar yang mengelilingi otolit. Luas area otolit (otolith area atau $\mathrm{O}_{\mathrm{A}}, \mathrm{mm}^{2}$ ) didefinisikan sebagai luas keseluruhan area/wilayah otolit yang dibatasi oleh garis terluar (Zorica et al. 2010, Aguera \& Brophy 2011, Zischke et al. 2016).

\section{Analisis data}

Data morfometri otolit kanan dan kiri diuji normalitas dan homogenitasnya menggunakan uji Kolmogorov-Smirnov dan uji Levene. Uji tberpasangan dua arah pada taraf kepercayaan 95\% juga diterapkan untuk menentukan signifikansi perbedaan data morfometri otolit kanan dan kiri.

Penentuan indeks bentuk otolit dilakukan dengan enam deskriptor terdiri atas form factor $\left(\mathrm{F}_{\mathrm{F}}\right)$, roundness $\left(\mathrm{R}_{\mathrm{O}}\right)$, circularity atau compactness $(\mathrm{C})$, rectangularity $\left(\mathrm{R}_{\mathrm{t}}\right)$, ellipticity $(\mathrm{E})$, dan aspect ratio $\left(\mathrm{A}_{\mathrm{R}}\right)$ menggunakan persamaan menurut Ponton (2006), Aguera \& Brophy (2011), Sadighzadeh et al. (2012), Bani et al. (2013), Zengin et al. (2015), Zischke et al. (2016), dan Avigliano et al. (2017) yang disajikan pada Tabel 1. Masing-masing deskriptor indeks bentuk selanjutnya dibandingkan antarlokasi untuk menentukan signifikansinya dengan analisis multivariate menggunakan MANOVA $(\alpha=0,05)$, kemudian dilanjutkan dengan uji Tuckey menggunakan piranti lunak SPSS versi 24. 
Tabel 1. Penghitungan indeks bentuk otolit menggunakan pengukuran morfometri beserta formulanya

\begin{tabular}{|c|c|c|}
\hline $\begin{array}{l}\text { Indeks } \\
\text { bentuk }\end{array}$ & Formula & Kegunaan \\
\hline $\mathrm{F}_{\mathrm{F}}$ & $4 \pi O_{A} / O_{P}^{2}$ & $\begin{array}{l}\text { Mengestimasi keteraturan pada permukaan otolit, dimana } \mathrm{F}_{\mathrm{F}}=1 \\
\text { menunjukkan permukaan yang teratur seperti lingkaran. Nilai } \mathrm{F}_{\mathrm{F}}<1 \text { berart } \\
\text { permukaan tidak teratur, sedangkan } \mathrm{F}_{\mathrm{F}}=1 \text { berarti permukaan teratur. }\end{array}$ \\
\hline $\mathrm{R}_{\mathrm{O}}$ & $4 O_{A} / \pi O_{L}^{2}$ & $\begin{array}{l}\text { Membandingkan bentuk otolit terhadap bentuk lingkaran penuh, di mana } \\
\mathrm{R}_{\mathrm{O}}=1 \text { menandakan bentuk lingkaran penuh. }\end{array}$ \\
\hline $\mathrm{C}$ & $O_{P}^{2} / O_{A}$ & Membandingkan bentuk otolit terhadap bentuk lingkaran penuh. \\
\hline $\mathrm{R}_{\mathrm{t}}$ & $O_{A} /\left(O_{L} \cdot O_{W}\right)$ & $\begin{array}{l}\text { Menggambarkan variasi panjang dan lebar otolit terhadap luas area, di } \\
\text { mana } \mathrm{R}_{\mathrm{t}}=1 \text { menggambarkan otolit berbentuk persegi sempurna. }\end{array}$ \\
\hline $\mathrm{E}$ & $\frac{O_{L}-O_{W}}{\left(O_{L}+O_{W}\right)}$ & Mengindikasikan terjadinya perubahan sumbu secara proporsional. \\
\hline$A_{R}$ & $O_{L} / O_{W}$ & $\begin{array}{l}\text { Menunjukkan bentuk otolit, di mana nilai } A_{R}>1 \text { menandakan bentuk otolit } \\
\text { yang cenderung memanjang. }\end{array}$ \\
\hline
\end{tabular}

Keterangan: $\mathrm{F}_{\mathrm{F}}=$ form factor, $\mathrm{R}_{\mathrm{O}}=$ roundness, $\mathrm{C}=$ circularity atau compactness, $\mathrm{R}_{\mathrm{t}}=$ rectangularity, $\mathrm{E}=$ ellipticity, dan $\mathrm{A}_{\mathrm{R}}=$ aspect ratio

\section{Hasil}

Secara keseluruhan didapatkan 253 pasang otolit ikan cakalang dengan ukuran panjang cagak berkisar antara 27-63 $\mathrm{cm}$ dan bobot tubuh 307-6.080 gram (Tabel 2). Hasil pengujian terhadap normalitas dan homogenitas data morfometri otolit $\left(\mathrm{O}_{\mathrm{M}}, \mathrm{O}_{\mathrm{L}}, \mathrm{O}_{\mathrm{W}}, \mathrm{O}_{\mathrm{P}}\right.$, danO $\left.\mathrm{A}_{\mathrm{A}}\right)$ dengan uji Kolmogorov-Smirnov dan Levene menunjukkan bahwa data morfometri otolit tersebar secara normal dan homogen $(\mathrm{P}>0,05)$. Hasil uji t berpasangan dua arah menunjukkan bahwa data morfometri otolit kanan dan kiri tidak berbeda nyata $(\mathrm{P}>0,05)$, kecuali pada parameter panjang otolit $\left(\mathrm{O}_{\mathrm{L}}\right)$ yang menunjukkan perbedaan yang nyata $(\mathrm{P}<0,05)$, yaitu otolit kanan lebih panjang daripada kiri. Selanjutnya, penghitungan indeks bentuk menggunakan data otolit kanan.

Penghitungan indeks bentuk otolit yang meliputi form factor $\left(\mathrm{F}_{\mathrm{F}}\right)$, roundness $\left(\mathrm{R}_{\mathrm{O}}\right)$, circularity atau compactness $(\mathrm{C})$, rectangularity $\left(\mathrm{R}_{\mathrm{t}}\right)$, ellipticity $(\mathrm{E})$, dan aspect ratio $\left(\mathrm{A}_{\mathrm{R}}\right)$ disajikan pada Gambar 3. Hasil pengujian terhadap variasi indeks bentuk otolit menggunakan MANOVA menunjukkan bahwa terdapat perbedaan yang nyata pada indeks bentuk otolit $F_{F}, C, E$, dan $A_{R}$ diantara ikan cakalang pada lokasi yang berbeda, sedangkan $R_{O}$ dan $R_{t}$ tidak berbeda nyata $(\mathrm{P}>0,05)$. Berdasarkan deskriptor $\mathrm{F}_{\mathrm{F}}$, secara umum otolit cakalang dari keempat lokasi memiliki kesamaan bentuk yaitu permukaan yang tidak teratur $\left(\mathrm{F}_{\mathrm{F}}<1\right)$. Tidak ditemukan signifikansi nilai $F_{F}$ antara lokasi Labuhan Lombok (LOM) dan Prigi (PRI), Binuangeun (BIN) dan Labuhan Lombok (LOM), serta Binuangen (BIN) dan Sadeng (SAD). Signifikansi nilai $F_{F}$ terjadi antara lokasi Prigi (PRI) dan Sadeng (SAD), yaitu $F_{F}$ Prigi (PRI) lebih kecil daripada $\mathrm{F}_{\mathrm{F}}$ Sadeng (SAD). Hal tersebut berarti permukaan otolit dari lokasi Prigi (PRI) lebih tidak beraturan atau berlekuk-lekuk dibandingkan Sadeng (SAD). Berdasarkan deskriptor $\mathrm{R}_{\mathrm{O}}$ dan $\mathrm{R}_{\mathrm{t}}$, otolit dari keempat lokasi tidak menunjukkan perbedaan yang nyata. $\mathrm{R}_{\mathrm{O}}$ dan $\mathrm{R}_{\mathrm{t}}$ dari keempat lokasi sama-sama bernilai kurang dari satu, menunjukkan bahwa otolit ikan cakalang dari keempat lokasi kurang membulat dan cenderung memanjang. Berdasarkan deskriptor C, signifikansi ditemukan antara lokasi Prigi (PRI) dan 
Binuangeun (BIN) serta Prigi (PRI) dan Sadeng (SAD). Berdasarkan deskriptor $\mathrm{E}$ dan $\mathrm{A}_{\mathrm{R}}$, signifikansi ditemukan antara lokasi Prigi (PRI) dan Labuhan Lombok (LOM). Secara keseluruhan, indeks bentuk otolit dapat mendemonstrasikan bentuk morfologi otolit ikan cakalang, yaitu cenderung oval, memanjang (persegi panjang), dan permukaan tidak beraturan (Gambar 4).

Tabel 2. Deskripsi statistik ukuran tubuh dan morfometri otolit populasi ikan cakalang di Samudra Hindia

\begin{tabular}{|c|c|c|c|c|c|c|c|}
\hline \multirow{2}{*}{ Daerah } & \multirow{2}{*}{$\begin{array}{l}\text { Panjang } \\
(\mathrm{cm})\end{array}$} & \multirow{2}{*}{$\begin{array}{l}\text { Bobot } \\
\text { (gram) }\end{array}$} & \multicolumn{5}{|c|}{$\begin{array}{l}\text { Deskripsi statistik parameter morfometri otolit } \\
\quad(\text { min-maks, rata-rata } \pm \text { simpangan baku) }\end{array}$} \\
\hline & & & $\mathrm{O}_{\mathrm{M}}(\mathrm{gram})$ & $\mathrm{O}_{\mathrm{L}}(\mathrm{mm})$ & $\mathrm{O}_{\mathrm{W}}(\mathrm{mm})$ & $\mathrm{O}_{\mathrm{P}}(\mathrm{mm})$ & $\mathrm{O}_{\mathrm{A}}\left(\mathrm{mm}^{2}\right)$ \\
\hline \multirow{2}{*}{$\begin{array}{l}\text { Binuangeun/ BIN } \\
(\mathrm{n}=88)\end{array}$} & \multirow[t]{2}{*}{$27-58$} & \multirow[t]{2}{*}{$307-3.738$} & $0,0017-0,0054$ & $3,197-5,388$ & $1,22-2,283$ & $9,97-26,197$ & $2,893-8,339$ \\
\hline & & & $0,003 \pm 0,0008$ & $4,345 \pm 0,544$ & $1,764 \pm 0,211$ & $14,786 \pm 2,627$ & $5,375 \pm 1,194$ \\
\hline \multirow{2}{*}{$\begin{array}{l}\text { Sadeng/ SAD } \\
(\mathrm{n}=52)\end{array}$} & \multirow[t]{2}{*}{$34-54$} & \multirow[t]{2}{*}{$663-3.395$} & \multirow{2}{*}{$\begin{array}{l}0,0019-0,0044 \\
0,003 \pm 0,0005\end{array}$} & $3,622-5,464$ & $1,539-2,082$ & $11,85-20,649$ & $4,132-7,367$ \\
\hline & & & & $4,509 \pm 0,365$ & $1,821 \pm 0,122$ & $14,862 \pm 1,566$ & $5,716 \pm 0,697$ \\
\hline \multirow{2}{*}{$\begin{array}{l}\text { Prigi/ PRI } \\
(\mathrm{n}=33)\end{array}$} & \multirow[t]{2}{*}{$35-51$} & \multirow[t]{2}{*}{$863-2.688$} & \multirow{2}{*}{$\begin{array}{l}0,0021-0,0042 \\
0,003 \pm 0,0005\end{array}$} & $3,881-4,908$ & $1,595-2,164$ & $13,303-24,657$ & $4,582-6,946$ \\
\hline & & & & $4,459 \pm 0,288$ & $1,837 \pm 0,11$ & $16,233 \pm 2,766$ & $5,694 \pm 0,585$ \\
\hline \multirow{2}{*}{$\begin{array}{l}\text { Labuhan Lombok/ } \\
\text { LOM }(n=80)\end{array}$} & \multirow[t]{2}{*}{$41-63$} & \multirow[t]{2}{*}{$1.276-6.080$} & \multirow{2}{*}{$\begin{array}{l}0,0021-0,0055 \\
0,003 \pm 0,0008\end{array}$} & $4,105-5,674$ & $1,595-2,451$ & $13,052-26,465$ & $4,904-8,656$ \\
\hline & & & & $4,747 \pm 0,372$ & $1,892 \pm 0,162$ & $16,458 \pm 2,211$ & $6,278 \pm 0,909$ \\
\hline
\end{tabular}



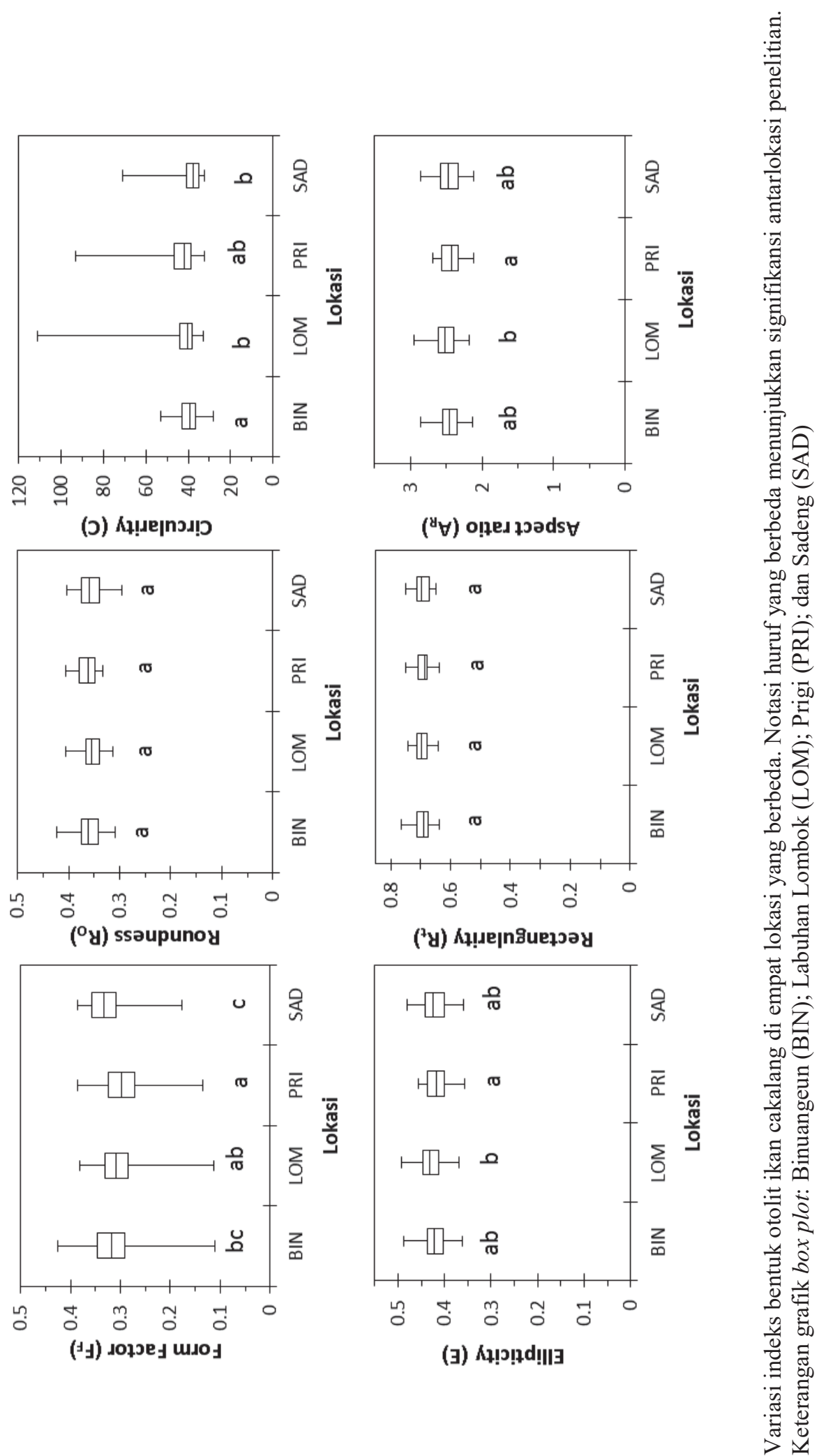

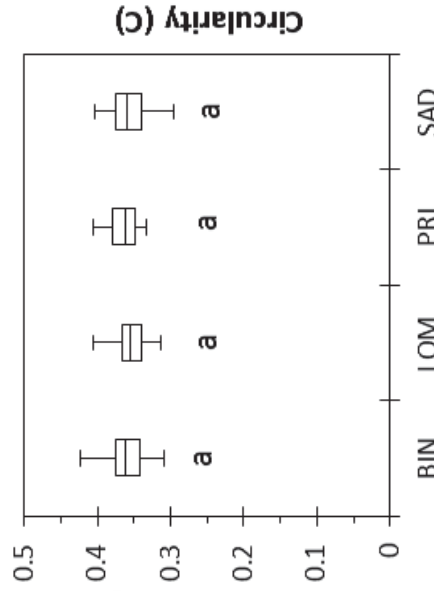

$\left({ }^{\circ} \mathrm{y}\right)$ ssaupunoy

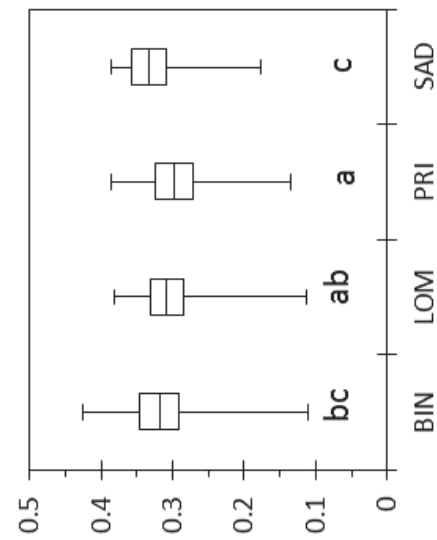

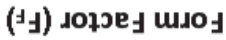

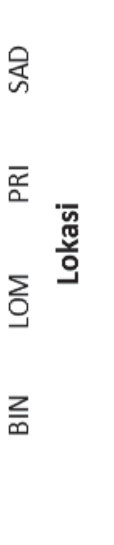

$\frac{1}{n}$
$\overline{\frac{x}{2}}$
$\sum_{0}^{\frac{5}{0}}$
$\frac{\pi}{9}$
( $\left.{ }^{4} \forall\right)$ O!̣ed ұəads $\forall$

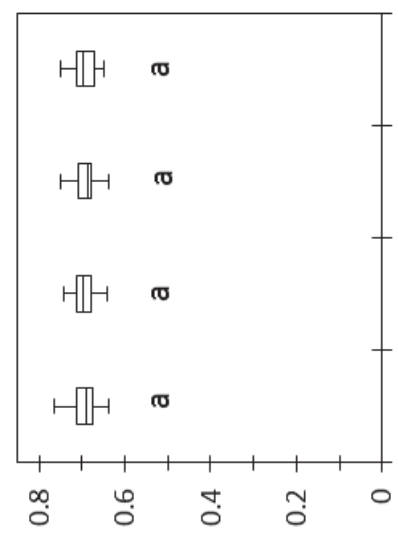

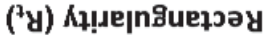

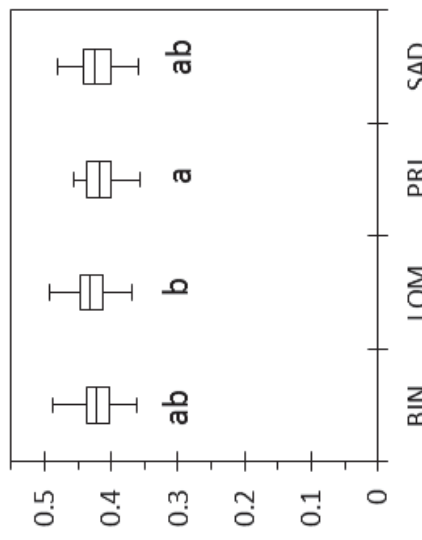

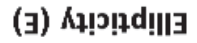

की 

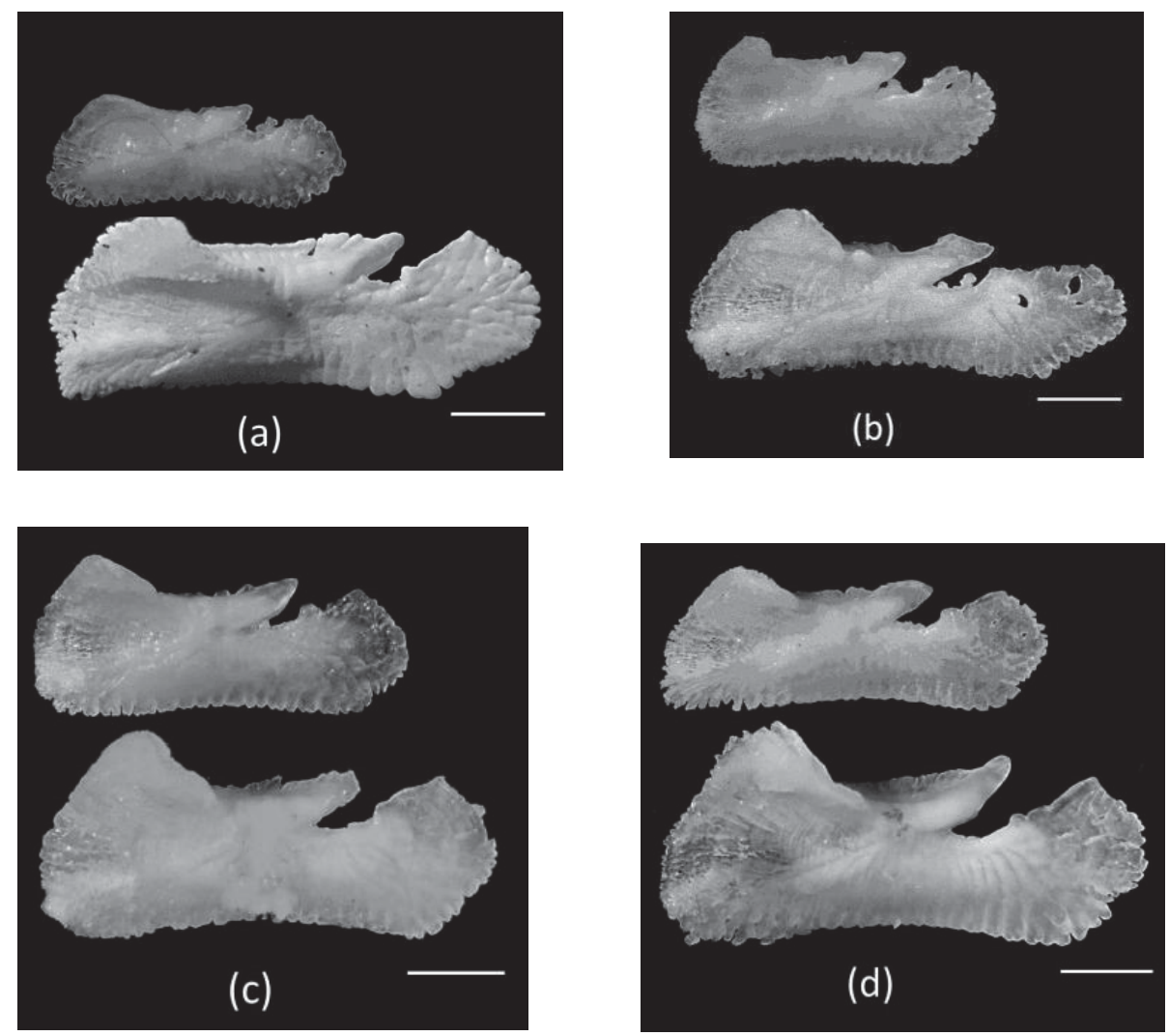

Gambar 4. Penampang lateral otolit ikan cakalang sebelah kanan dari empat lokasi di Samudra Hindia; (a) Binuangeun ukuran panjang cagak ikan adalah 27 dan $58 \mathrm{~cm}$, (b) Sadeng ukuran panjang cagak 34 dan $53 \mathrm{~cm}$, (c) Prigi ukuran panjang cagak 35 dan $51 \mathrm{~cm}$, dan (d) Labuhan Lombok ukuran panjang cagak 41 dan $63 \mathrm{~cm}$. Skala batang berwarna putih menandakan $1 \mathrm{~mm}$

\section{Pembahasan}

Penelitian indeks bentuk sagittae otolit telah dilakukan sebelumnya dengan menggunakan deskriptor yang berbeda-beda. Penelitian terhadap kelompok ikan genus Serranus di Kepulauan Canary, Spanyol menggunakan enam deskriptor (Tuset et al. 2003, 2006), tiga spesies Caspian Goby selatan di Pantai Anzali, Iran menggunakan enam deksriptor (Bani et al. 2013), dan lima jenis ikan pelagis di Laut Adriatic, Kroasia menggunakan tiga deksriptor (Zorica et al. 2010). Penggunaan deskriptor seringkali berkaitan dengan studi lanjutan penggunaan bentuk otolit dalam menginvestigasi struktur populasi ikan peruaya yang tersebar secara luas pada area perairan yang berbeda (Burke et al. 2008, Aguera
\& Brophy 2011, Hussy et al. 2016, Wujdi et al. 2017).

Hasil penelitian ini mengungkap bahwa parameter morfometri $\mathrm{O}_{\mathrm{M}}$ dan $\mathrm{O}_{\mathrm{W}}$ antara otolit kanan dan kiri tidak berbeda nyata. Hasil penelitian ini selaras dengan penelitian sebelumnya pada beberapa jenis ikan famili Scombridae, seperti Rastrelliger kanagurta di perairan Oman, Scomber japonicus di perairan Laut Cina Selatan, Scomber australasicus di Teluk Sagami, Jepang, dan Scomber scombrus di Laut Norwegia (Jawad et al. 2011, He et al. 2017).

Nilai indeks bentuk otolit ikan cakalang bervariasi antarlokasi yang berbeda, khususnya pada deskriptor $F_{F}, C, E$, dan $A_{R}$, sedangkan $R_{O}$ dan $\mathrm{R}_{\mathrm{t}}$ tidak berbeda nyata $(\mathrm{P}>0,05)$. Variasi ini dapat dipengaruhi oleh perbedaan kondisi ling- 
kungan perairan (Campana \& Neilson 1985, Campana \& Casselman 1993), ketersediaan makanan dan suhu perairan (Cardinale et al. 2004, Vignon 2012), ontogenetik (Cardinale et al. 2004), serta perbedaan demografi seperti jenis kelamin, umur, dan populasi (Nielsen et al. 2010, Bostanci et al. 2015). Namun demikian, berdasarkan nilai indeks bentuknya, secara umum bentuk morfologi otolit ikan cakalang di empat lokasi masih berada pada kisaran yang sama sehingga dapat merepresentasikan bentuk otolit yang sama pula. Otolit ikan cakalang berbentuk cenderung oval, memanjang dan memiliki pinggiran yang tidak teratur.

Otolit ikan cakalang memiliki permukaan luar yang tidak beraturan dan cenderung berlekuk-lekuk ditunjukkan dengan nilai $\mathrm{F}_{\mathrm{F}}<1$. Nilai $\mathrm{R}_{\mathrm{O}}<1$ dan $\mathrm{C}$ pada penelitian ini memperlihatkan sagittae otolit cenderung berbentuk oval daripada berbentuk bulat, sedangkan nilai $\mathrm{R}_{\mathrm{T}}<1, \mathrm{E}$ dan $A_{R}>1$ menunjukkan bahwa sagittae otolit cenderung memanjang. Hasil penelitian ini selaras dengan penelitian sebelumnya, yaitu bentuk otolit ikan cakalang di perairan Brazil dan Samudra Atlantik adalah memanjang, oval dan meruncing di bagian ujung anterior seperti halnya mata tombak ditunjukkan dengan nilai $\mathrm{R}_{\mathrm{T}}<1$ (Tuset et al. 2008, Santificetur et al. 2017). Bentuk sagittae yang cenderung oval, memanjang, dan meruncing pada bagian anterior ini menjadi ciri khas ikan pelagis. Perbedaan bentuk otolit, khususnya bagian sagittae, antara ikan pelagis dan demersal terletak pada ketebalan dan tingkat kebulatan. Ikan pelagis dengan kebiasaan berenang yang aktif memiliki sagittae yang tipis dan memanjang, sedangkan ikan demersal yang hidup di dasar perairan memiliki sagittae yang tebal dan membulat (Gauldie \& Crampton 2002, Bani et al. 2013).
Dalam penelitian ini, terdapat perbedaan yang nyata pada nilai deskriptor $F_{F}, C, E$ dan $A_{R}$ antar lokasi penelitian. Menurut Avigliano et al. (2017), Aguera \& Brophy (2011), Ferguson et al. (2011) deskriptor $\mathrm{C}$, E, dan $\mathrm{F}_{\mathrm{F}}$, dapat digunakan sebagai indikator habitat untuk membedakan daerah pemijahan jenis ikan Prochilodus lineatus, Scomberesox saurus, dan Argyrosomus japonicus. Dalam penelitian ini, nilai deskriptor $\mathrm{R}_{\mathrm{t}}$ tidak berbeda nyata antar lokasi. Hal ini berarti $R_{t}$ kurang efisien apabila digunakan untuk membedakan habitat ikan. Pernyataan ini didukung hasil penelitian sebelumnya oleh Aguera \& Brophy (2011) pada ikan Scomberesox saurus dan Duarte-Neto et al. (2008) pada ikan Coryphaena hippurus. Hasil penelitian ini menunjukkan bahwa nilai deskriptor $\mathrm{R}_{\mathrm{O}}$ juga tidak berbeda nyata antarlokasi sehingga juga kurang efisien untuk membedakan habitat ikan. Namun demikian, hasil penelitian ini berbeda dengan penelitian sebelumnya oleh Ferguson et al (2011) dan Aguera \& Brophy (2011) yang menyatakan bahwa $R_{O}$ merupakan indikator yang ideal untuk membedakan habitat ikan A. japonicus dan S. saurus. Penelitian ini dapat membuktikan bahwa bentuk otolit dapat diterapkan untuk membedakan struktur populasi dan area pemijahan ikan dari perairanperairan yang berbeda, seperti halnya telah diteliti sebelumnya oleh Wujdi et al. (2017), Libungan et al. (2015), dan Avigliano et al. (2017).

\section{Kesimpulan}

Parameter morfometri otolit kanan dan kiri tidak berbeda nyata. Berdasarkan analisis indeks bentuk dengan menggunakan enam deskriptor, otolit ikan cakalang, khususnya bagian sagittae, memiliki karakteristik yang khas yaitu berbentuk oval yang meruncing di bagian anterior seperti mata tombak, cenderung memanjang, dan permukaannya tidak teratur. 


\section{Persantunan}

Artikel ini merupakan kontribusi dari kegiatan penelitian yang berjudul "Penelitian Karakteristik Ekobiologi Ikan Pelagis di Sekitar Rumpon di WPP NRI-573 (Samudra Hindia Selatan Jawa hingga Nusa Tenggara)" yang dilaksanakan oleh Loka Penelitian Perikanan Tuna (LP2T) dengan sumber dana DIPA tahun anggaran 2016.

\section{Daftar pustaka}

Aguera A, Brophy D. 2011. Use of saggital otolith shape analysis to discriminate Northeast Atlantic and Western Mediterranean stocks of Atlantic saury, Scomberesox saurus saurus (Walbaum). Fisheries Research, 110(3): 465-471. https://doi.org/ 10.1016/j.fishres.2011.06.003

Annabi A, Said K, Reichenbacher B. 2013. Interpopulation differences in otolith morphology are genetically encoded in the killifish Aphanius fasciatus (Cyprinodontiformes). Scientia Marina, 77(2): 269-279. https://doi.org/10.3989/scimar.03763.02A

Avigliano E, Domanico A, Sanchez S, Volpedo AV. 2017. Otolith elemental fingerprint and scale and otolith morphometry in Prochilodus lineatus provide identification of natal nurseries. Fisheries Research, 186: 1-10. http://doi.org/10.1016/j.fishres.2016. 07.026

Aydin R, Calta M, Dursun S, Coban MZ. 2004. Relationships between fish lengths and otolith length in the population of Chondrostoma regium (Heckel, 1843) Inhabiting Keban Dam Lake. Pakistan Journal of Biology Science, 7(9): 1550-1553. https: //doi. org/10.3923/pjbs.2004.1550.1553

Bani A, Poursaeid S, Tuset VM. 2013. Comparative morphology of the sagittal otolith in three species of south Caspian Gobies. Journal of Fish Biology, 82(4): 13211332. https://doi.org/10.1111/jfb.12073

Bostanci D, Polat N, Kurucu G, Yedier S, Kontas S, Darcin M. 2015. Using otolith shape and morphometry to identify four Alburnus species (A. chalcoides, A. escherichii, A. mossulensis and A. tarichi) in Turkish inland waters. Journal of Applied Ichthyology, 31(6): 1013-1022. https://doi. org/10.1111/jai.12860

Burke N, Brophy D, King PA. 2008. Otolith shape analysis: its application for discriminating between stocks of Irish Sea and Celtic Sea herring (Clupea harengus) in the Irish Sea. ICES Journal of Marine Science, 65(9): 1670-1675. https://doi. org/10.1093/icesjms/fsn177

Cabello MG, Barr EE, Solís EGC, Gómez MP, Boa AG. 2014. Morphometric analysis on sagitta, asteriscus and lapillus of Shortnose Mojarra Diapterus brevirostris (Teleostei: Gerreidae) in Cuyutlan coastal Lagoon, Colima, Mexico. Revista de Biologia Marina Y Oceanografia, 49(2): 209-223. https://doi.org/10.4067/S071819572014000200004

Campana SE. 2004. Photographic atlas of fish otoliths of the Northwest Atlantic Ocean. Canadian Special Publication of Fisheries and Aquatic Science Vol. 133. NRC Research Press, Ottawa, Canada. 284 p.

Campana SE, Casselman JM. 1993. Stock discrimination using otolith shape-analysis. $\mathrm{Ca}$ nadian Journal of Fisheries and Aquatic Sciences, 50(5): 1062-1083. https://doi. org/10.1139/f93-123

Campana SE, Neilson JD. 1985. Microstructure of fish otoliths. Canadian Journal of Fisheries and Aquatic Sciences, 42(5): 1014-1032. https://doi.org/10.1139/f85127

Cardinale M, Doering-Arjes P, Kastowsky M, Mosegaard H. 2004. Effects of sex, stock, and environment on the shape of knownage Atlantic cod (Gadus morhua) otoliths. Canadian Journal of Fisheries and Aquatic Science 61(2): 158-167

Chulin AK, Chen HM. 2013. Comparative morphological study of otoliths in Taiwanese anguilliformes fishes. Journal of Marine Science and Technology, 21: 77-85. https://doi.org/10.6119/JMST-013-1220-3

Duarte-Neto P, Lessa R, Stosic B, Morize E. 2008. The use of sagittal otoliths indiscriminating stocks of common dolphinfish (Coryphaena hippurus) off northeastern Brazil using multishape descriptors. ICES Journal of Marine Science 65(7): 11441152. http://doi.org/10.1093/icesjms/ fsn090 
Essington TE, Hunsicker ME, Olson RJ, Maunder MN, Kitchell JF. 2009. Predation, cannibalism, and the dynamics of tuna populations. Pelagic Fisheries Research Program, 14(1): 1-4.

Ferguson GJ, Ward TM, Gillanders BM. 2011. Otolith shape and elementalcomposition: complementary tools for stock discrimination of mulloway (Argyrosomus japonicus) in southern Australia. Fisheries Research, 110(1): 75-83. http://doi.org/10. 1016/j.fishres.2011.03.014

Fonteneau A, Nishida T, Nakamura I, Seret B. 2009. Schooling finfish: an overview of the tunas, billfishes, and sharks. In: P. Safran (ed.), Fisheries and Aquaculture. Oxford, United Kingdom: EOLSS Publishers Co. Ltd. pp. 42-79.

Gauldie RW, Crampton JS. 2002. An ecomorphological explanation of individual variability in the shape of the fish otolith: comparison of the otolith of Hoplostethus atlanticus with other species by depth. Journal of Fish Biology, 60(5): 12041221. https://doi.org/10.1006/jfbi.2002. 1938

He T, Cheng J, Qin J, Li Y, Gao T. 2017. Comparative analysis of otolith morphology in three species of Scomber. Ichthyological Research, 65(2): 192-201. http://doi.org/ 10.1007/s10228-017-0605-4

Homayuni H, Marjani M, Sabet HM. 2013. Descriptive key to otoliths of three Sardinella species (Pisces, Clupeidae) from the Northern Oman Sea. AACL Bioflux, 6(3): 211-221.

Hunsicker ME, Olson RJ, Essington TE, Maunder MN, Duffy LM, Kitchell JF. 2012. Potential for top-down control on tropical tunas based on structure of predator-prey interactions. Marine Ecology Progress Series, 445: 263-277. https://doi.org/ $10.3354 /$ meps09404

Hussy K, Mosegaard H,Albertsen CM, Nielsen EE, Hansen JH, Eero M. 2016. Evaluation of otolith shape as a tool for stock discrimination in marine fishes using Baltic Sea cod as a case study. Fisheries Research, 174: 210-218. https://doi.org/10.1016/ j.fishres.2015.10.010

Jawad LA, Al-Jufaili SA, Al-Shuhaily SS. 2008. Morphology of the otolith of the greater lizardfish Saurida tumbil (Pisces: Synodontidae). Journal of Natural History,
42(35-36): 2321-2330. https://doi.org/10. 1080/00222930802130278

Jawad LA, Ambuali A, Al-Mamry JM, Al-Busaidi HK. 2011. Relationship between fish length and otolith length, width and weight of the Indian mackerel Rastrelliger kanagurta (Cuvier, 1817) collected from the Sea of Oman. Ribarstvo, 69(2): 51-61.

Libungan LA, Palsson S. 2015. ShapeR: An R Package to study otolith shape variation among fish populations. PLOS ONE, 10(3): 1-12. https://doi.org/10.1371/ journal.pone.0121102

Libungan LA, Oskarsson GJ, Slotte A, Jacobsen JA, Palsson S. 2015. Otolith shape: a population marker for Atlantic herring Clupea harengus. Journal of Fish Biology, 86(4): 1377-1395. https://doi.org/10.1111 /jfb. 12647

Nielsen JR, Methven DA, Kristensen K. 2010. A statistical discrimination method using sagittal otolith dimensions between sibling species of juvenile cod Gadus morhua and Gadus ogac from the northwest Atlantic. Journal of Northwest Atlantic Fishery Science, 43: 27-45. https://doi.org/10. 2960/J.v43.m667

Pascoe PL. 1986. Fish otoliths from the stomach of a thresher shark. Journal of the Marine Biological Association of the United Kingdom, 66(2), 315-317. https://doi.org/ $10.1017 / \mathrm{S} 0025315400042958$

Polito MJ, Trivelpiece WZ, Karnovsky NJ, Elizabeth $\mathrm{Ng}$, Patterson WP, Emslie SD. 2011. Integrating stomach content and stable isotope analyses to quantify the diets of pygoscelid penguins. PLOS ONE, 6(10): 1-10. https://doi.org/10.1371/ journal.pone. 0026642

Ponton D. 2006. Is geometric morphometrics efficient for comparing otolith shape of different fish species?. Journal of Morphology, 267(6): 750-757. https://doi.org/ 10.1002/jmor

Popper AN, Ramcharitar J, Campana SE. 2005. Why otoliths? Insights from inner ear physiology and fisheries biology. Marine and Freshwater Research, 56(5): 497504. https://doi.org/10.1071/MF04267

Reichenbacher B, Reichard M. 2014. Otoliths of five extant species of the annual killifish 
Nothobranchius from the East African savannah. PLoS ONE, 9(11): 1-12. https: //doi.org/10.1371/journal.pone.0112459

Reichenbacher B, Sienknecht U, Küchenhoff H, Fenske N. 2007. Combined otolith morphology and morphometry for assessing taxonomy and diversity in fossil and extant killifish (Aphanius, Prolebias). Journal of Morphology, 268(10): 898-915. https://doi.org/10.1002/jmor.10561

Sadighzadeh Z, Otero-Ferrer JL, Lombarte A, Fatemi MR, Tuset VM. 2014. An approach to unraveling the coexistence of snappers (Lutjanidae) using otolith morphology. Scientia Marina, 78(3): 353362 . https://doi.org/10.3989/scimar. $03982.16 \mathrm{C}$

Sadighzadeh Z, Tuset VM, Valinassab T, Dadpour MR, Lombarte A. 2012. Comparison of different otolith shape descriptors and morphometrics for the identification of closely related species of Lutjanus spp. from the Persian Gulf. Marine Biology Research, 8(9): 802-814. https://doi.org/ $10.1080 / 17451000.2012 .692163$

Santificetur C, Conversani VRM, Brenha-Nunes MR, Giaretta MB, Siliprandi CC, RossiWongtschowski CLDB. 2017. Atlas of marine bony fish otoliths (sagittae) of Southeastern-Southern Brazil Part V: Perciformes (Sparidae, Sciaenidae, Polynemidae, Mullidae, Kyphosidae, Chaetodontidae, Mugilidae, Scaridae, Percophidae, Pinguipedidae, Blenniidae, Gobiidae, Ephippidae, Sphyraenidae, Gempylidae, Trichiuridae, Scombridae, Ariommatidae, Stromateidae and Caproidae). Brazilian Journal of Oceanography, 65(2): 201-257. http://doi.org/10.1590/S167987592017131006502

Secor DH, Dean JM, Laban EH. 1992. Otolith removal and preparation for microchemical examination. In: D.Stevenson and S. Campana (Eds), Otolith microstructure examination and analysis. Canadian Special Publication of Fisheries and Aquatic Sciences Volume. 117. Ottawa, Canada: pp. 19-57.

Seyfabadi J, Afshari M, Valinassab T. 2014. Otolith morphology and body size relationships of Nemipterus japonicus (Bloch, 1791) in the Northern Oman Sea. Indian Journal of Fisheries, 61(2): 112-117.

Sparre P, Venema SC. 1999. Introduksi Pengkajian Ikan Tropis Buku 1: Manual. Diterje- mahkan oleh Pusat Penelitian dan Pengembangan Perikanan. Badan Penelitian dan Pengembangan Pertanian. Jakarta. $438 \mathrm{p}$.

Tuset VM, Lombarte A, Assis CA. 2008. Otolith atlas for the western Mediterranean, north and central eastern Atlantic. Scientia Marina, 72(72S1): 7-198. https://doi.org/ $10.3989 /$ scimar.2008.72s 17

Tuset VM, Lombarte A, González JA, Pertusa JF, Lorente MJ. 2003. Comparative morphology of the sagittal otolith in Serranus spp. Journal of Fish Biology, 63(6): 14911504. $\quad$ https://doi.org/10.1111/j.1095$\underline{8649.2003 .00262 . x}$

Tuset VM, Rosin PL, Lombarte A. 2006. Sagittal otolith shape used in the identification of fishes of the genus Serranus. Fisheries Research, 81(2-3): 316-325. https://doi.org /10.1016/j.fishres.2006.06.020

Valinassab T, Seyfabadi J, Homayuni H, Afraie Bandpei MA. 2012. Relationships between fish size and otolith morphology in ten clupeids from the Persian Gulf and Gulf of Oman. Cybium, 36(4): 505-509.

Vignon M. 2012. Ontogenetic trajectories of otolith shape during shift in habitat use: interaction between otolith growth and environment. Journal of Experimental Marine Biology and Ecology, 420-421: 26-32. https://doi.org/10.1016/j.jembe. 2012.03.021

Wujdi A, Setyadji B, Nugroho SC. 2017. Identifikasi struktur stok ikan cakalang (Katsuwonus pelamis Linnaeus, 1758) di Samudra Hindia (WPP NRI 573) menggunakan analisis bentuk otolith. Jurnal Penelitian Perikanan Indonesia, 23 (2): 77-88. http: //doi.org/10.15578/jppi.23.2.2017.77-88

Yilmaz S, Yazicioglu O, Saygin S, Polat N. 2014. Relationships of otolith dimensions with body length of European perch, Perca fluviatilis L., 1758 from Lake Ladik, Turkey. Pakistan Journal of Zoology, 46(5): 1231-1238.

Yilmaz S, Yazicioglu O, Yazici R, Polat N. 2015. Relationships between fish length and otolith size for five cyprinid species from Lake Ladik, Samsun, Turkey. Turkish Journal of Zoology, 39(3): 438446. https://doi.org/10.3906/zoo-1403-58

Zengin M, Saygin S, Polat N. 2015. Otolith shape analyses and dimensions of the An- 
chovy Engraulis encrasicolus L in the Black and Marmara Seas. Sains Malaysiana, 44(5), 657-662.

Zischke MT, Litherland L, Tilyard BR, Stratford NJ, Jones EL, Wang Y. 2016. Otolith morphology of four mackerel species (Scomberomorus spp.) in Australia: Species differentiation and prediction for fisheries monitoring and assessment. Fisheries Research, 176: 39-47. https: //doi.org/10.1016/j.fishres.2015.12.003

Zorica B, Sinovèiæ G, Èikeškeè V. 2010. Preliminary data on the study of otolith morphology of five pelagic fish species from the Adriatic Sea (Croatia). Acta Adriatica, 51(1): 89-96. 